\title{
Morphometry of the hyoid bone: a radiological anatomy study
}

\author{
Ahmet Dursun $^{1}$ (D), Mehtap Ayazoğlu ${ }^{1}$ (D), Veysel Atilla Ayyıldız ${ }^{2}$ (D), Yadigar Kastamoni ${ }^{1}$ (D), \\ Kenan Öztürk ${ }^{1}$ iD, Soner Albay ${ }^{1}$ iD \\ ${ }^{1}$ Department of Anatomy, School of Medicine, Siileyman Demirel University, Isparta, Turkey \\ ${ }^{2}$ Department of Radiology, School of Medicine, Siileyman Demirel University, Isparta, Turkey
}

\begin{abstract}
Objectives: The hyoid bone occupies a strategic position and participates in vital functions. The aim of this study was to examine the morphometry of the hyoid bone and define its location according to the vertebral level on 3D computed tomography $(\mathrm{CT})$ images.
\end{abstract}

Methods: This study was conducted using 3D-CT images of 216 patients (104 males, 112 females) aged between 10-98 years. The vertebral level of the hyoid bone was determined for each decade. Furthermore, the anterior-posterior length of the hyoid bone, the length and height of the greater horn, the height and width of the body, the distance between the posterior ends of the greater horn, and the distance of the hyoid bone to the vertebral column and the angle between right and left greater horn was measured.

Results: The hyoid bone was most commonly located at C3 and C2-C3 vertebral level in females (35.7\%) and C3 in males (38.5\%). No statistically significant difference was found between right and left sides concerning the length and height of the greater horn.

Conclusion: Knowing the radiological anatomy, morphometric properties and vertebral levels of the hyoid bone will contribute to the surgical planning of this region and the hyoid bone. In addition, our study will provide data on the morphometric properties of hyoid bone in forensic and anthropological research.

Keywords: greater horn; lesser horn; morphometry; computed tomography

Anatomy 2021;15(1):44-51 C2021 Turkish Society of Anatomy and Clinical Anatomy (TSACA)

\section{Introduction}

The neck involves vital anatomical structures such as the respiratory tract, arteries, veins, and nerves. Even a slight blow to the neck region may threaten one's health and life. Neck injuries may lead to hemorrhage in the neck muscles to fractures in the laryngeal cartilage and hyoid bone that can cause sudden death. ${ }^{[1]}$

The hyoid bone is located between the thyroid cartilage and the mandible in the anterior region of the neck, usually at the level of the C3 vertebra. ${ }^{[2]}$ It does not directly make articulation with any bone. It has a body and two protrusions called the greater and the lesser horns. ${ }^{[3]}$ The hyoid bone occupies a strategic position and participates in important vital functions. It is intimately connected to the larynx and plays a part in phonation, respiration, speech, and swallowing. ${ }^{[4]}$ The hyoid bone also serves as an insertion point for swallowing and respiratory muscles due to its position. ${ }^{[3]}$ During the pharyngeal phase of swallowing, the suprahyoid muscles contract, and the hyoid bone moves forward under the base of the tongue. Dysphagia, aspiration, and swallowing disorders can be seen as a side effect of the treatment of head and neck cancer with chemoradiotherapy resulting in decreased movement of the hyoid bone during swallowing. This can cause impaired closure of airway

This study was an oral presentation in the 20th National Anatomy Congress, 27tb-31st August 2019, Istanbul, Turkey. 
increasing the risk of aspiration. ${ }^{[5]}$ Therefore, it is important to know the morphometric characteristics and topography of the hyoid bone to provide an ideal surgical approach and plan radiotherapy. ${ }^{[3]}$

The hyoid bone syndrome is characterized by sensitivity and pain around the greater horn of the hyoid bone. The surgical removal of the greater horn is used for treatment of hyoid bone syndrome. ${ }^{[6]}$ Knowledge of the morphometric characteristics and variations of the hyoid bone is essential for the treatment of this syndrome. ${ }^{[7]^{\circ}}$

The hyoid bone fractures are regarded as the evidence of drowning or hanging in forensic medicine. ${ }^{[8]}$ The hyoid bone fractures have been associated with other injuries such as thyroid and cricoid cartilage fractures, and cervico-spinal fractures. The hyoid bone fractures are more common in males compared to females since blunt trauma, firearm injuries, sports-related injuries, falls, and attacks are more commonly seen in males. However, the incidence of the hyoid bone fractures is higher in females in relation to suicide attempts by hanging. The hyoid bone fractures, which occur with other bone fractures within head and neck fractures, are observed at a rate of $1.15 \%$. The ratio of isolated hyoid bone fractures is as low as $0.002 \%$ among all head and neck fractures. This ratio increases to $27-50 \%$ in cases such as suicide by hanging. ${ }^{[9]}$

Since the topography of the hyoid bone varies in between individuals, the location and morphometric characteristics of the hyoid bone should be known while evaluating this bone. Therefore, in this study, it was aimed to determine the location of the hyoid bone according to vertebral level, to examine its morphometry, to determine its distance to the vertebral column and to make a comparison between decades on three-dimensional computed tomography (3D-CT) images.

\section{Materials and Methods}

This study was conducted on 3D-CT images of 216 patients (104 males, 112 females) between 10 and 98 years of age. The patients were admitted to the hospital for any other reason rather than complaints or pathologies in the neck region. The age groups were divided into decades, including 2nd decade (10-19 years), 3rd decade (20-29 years), 4th decade (30-39 years), 5 th decade (40-49 years), 6th decade (50-59 years), 7th decade (60-69 years), 8th decade (70-79 years), 9th decade (80-89 years), and 10th decade (90-98 years). The cases in the first decade (0-9 years) were not included in the study because the hyoid bone ossification was not completed yet and could be misleading for measurements.
The images were obtained from our hospital's "Image Picture Archiving and Communication System." Multislice spiral CT scans were obtained with a multidetector 128 slice SOMATOM Definition AS Siemens (Siemens Healthcare, Erlangen, Germany) CT using the following parameters: $120 \mathrm{kV}$, effective mAs=143 mAs, slice thickness $=1 \mathrm{~mm}$, matrix $=512 \times 512$, collimation= $128 \times 0.6$ slice increment $=0.7$ pitch $=0.8$ FOV (Field of View) (250-300). A 3D reconstruction was created from scanned images using RadiAnt DICOM Viewer (Version 2020.1; Swansea, UK) programme.

The landmarks and parameters used for the measurements are presented in Table $\mathbf{1}$. While the angle between right and left greater horn was measured by the Image J program (Public Domain, BSD-2), other parameters were measured by RadiAnt DICOM Viewer (Version 2020.1; Swansea, UK) program. Our measurements were performed from the superior for the A, B, C, H, and $\alpha$ parameters, from the anterior for the $\mathrm{F}$ and $\mathrm{G}$ parameters, from the right lateral for the $\mathrm{D}$ parameter, and from the left lateral for the E and I parameters (Figures 1, 2 and 3).

While determining the vertebral level of the hyoid bone, we draw two lines parallel to the long axis of the hyoid bone from the top and bottom points on the left lateral side of the hyoid bone to the vertebral column so that the position of the head would not change the vertebral level. The point where these lines corresponded to the body of the vertebra was considered as the vertebral level (Figure 3). While measuring the distance of the hyoid bone to the vertebral column, we measured the shortest distance of the hyoid bone to the left lateral side of the vertebral column (Figure 3). Finally, we measured the angle

Table 1

Landmarks and parameters used for measurements.

\begin{tabular}{ll}
\multicolumn{2}{l}{ Landmark/parameter } \\
\hline A & Anterior-posterior lenght of the hyoid bone \\
\hline B & Lenght of the greater horn (right) \\
\hline C & Lenght of the greater horn (left) \\
\hline D & Height of the greater horn (right) \\
\hline E & Height of the greater horn (left) \\
\hline F & Width of the body of the hyoid bone \\
\hline $\mathrm{G}$ & Height of the body of the hyoid bone \\
\hline H & $\begin{array}{l}\text { The distance between the midpoints of the posterior ends of the } \\
\text { greater horn of the hyoid bone }\end{array}$ \\
\hline I & $\begin{array}{l}\text { The distance of the hyoid bone to the vertebral column (The distance } \\
\text { from the greater horn's posterior end to the vertebral column on the } \\
\text { line drawn parallel to its long axis) }\end{array}$ \\
\hline$\alpha\left(^{\circ}\right)$ & $\begin{array}{l}\text { Angle of right and left greater horn (The angle between greater horn } \\
\text { by connecting the lines passing through the midpoints of the anterior } \\
\text { and posterior ends of the greater horn) }\end{array}$ \\
\hline
\end{tabular}

' $\alpha$ ' symbolizes angle, other measurements are in milimeters. 

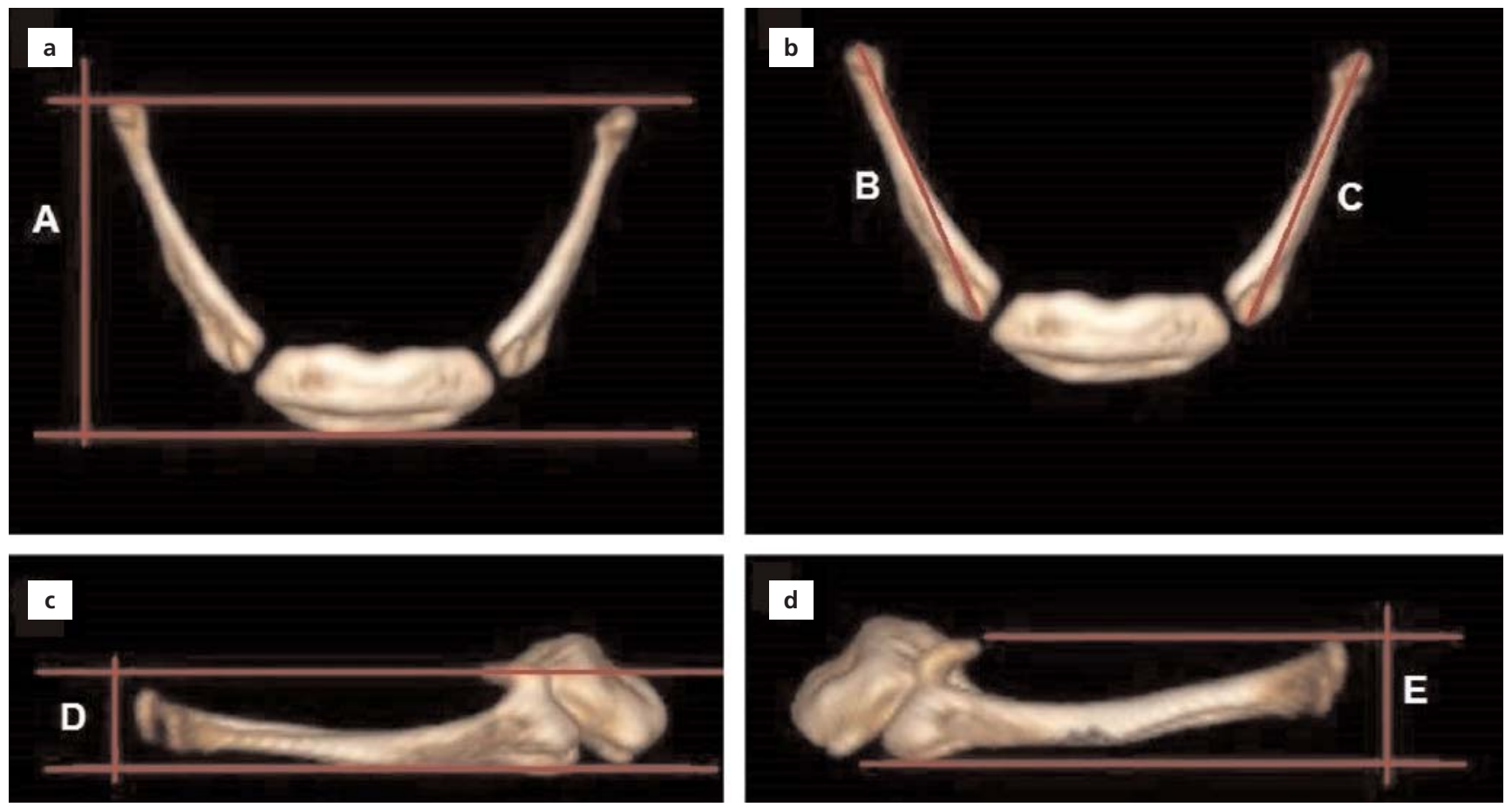

Figure 1. (a, b) Superior views. (c) Right lateral view. (d) Left lateral view. A: anterior-posterior lenght of the hyoid bone; B: lenght of the greater horn (right); C: lenght of the greater horn (left); D: height of the greater horn (right); E: height of the greater horn (left).

between right and left greater horn by connecting the lines passing through the midpoints of the anterior and posterior ends of the greater horn (Figure 2c). In order to increase the sensitivity for the measurements, the parameters were measured twice by two different researchers and the average of the two values was reported.
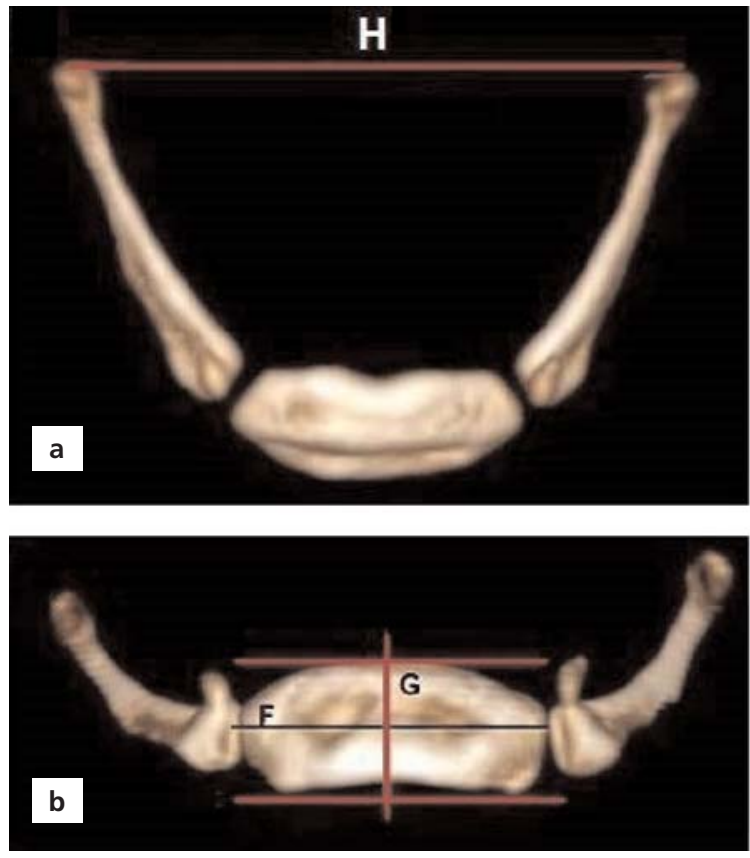

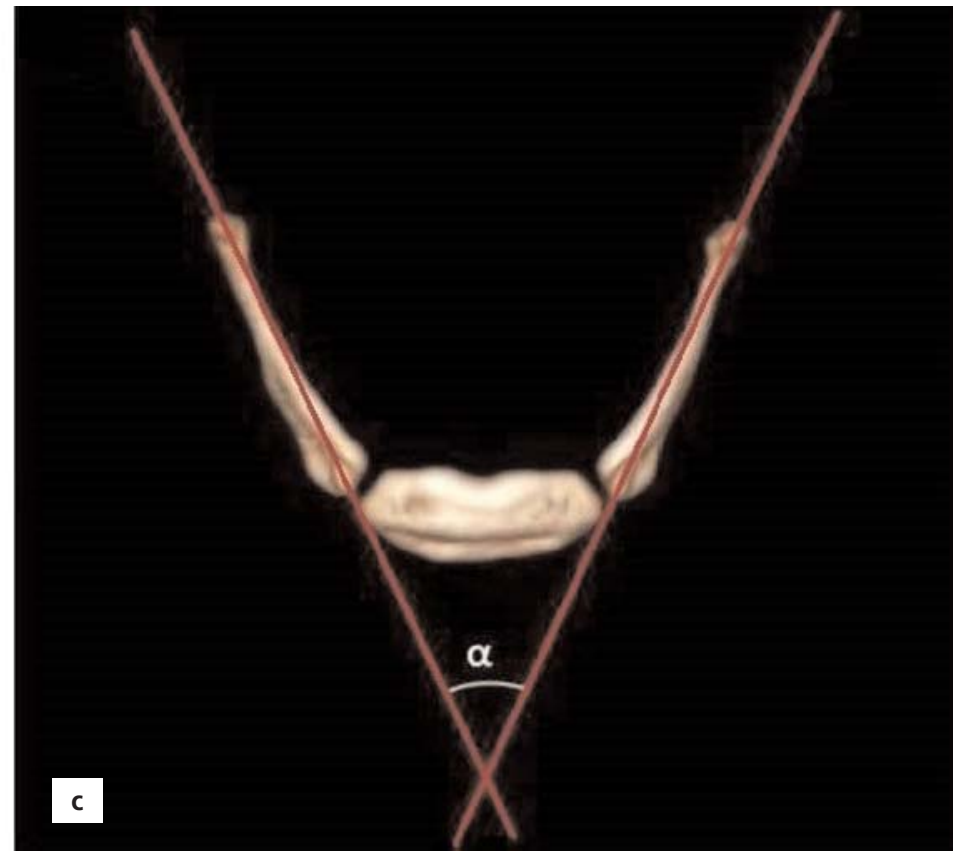

Figure 2. (a, c) Superior views. (b) Anterior view. F: width of the body of the hyoid bone; G: height of the body of the hyoid bone; $\mathrm{H}$ : the distance between the posterior ends of the greater horn; $\boldsymbol{\alpha}$ : angle between right and left greater horns. 


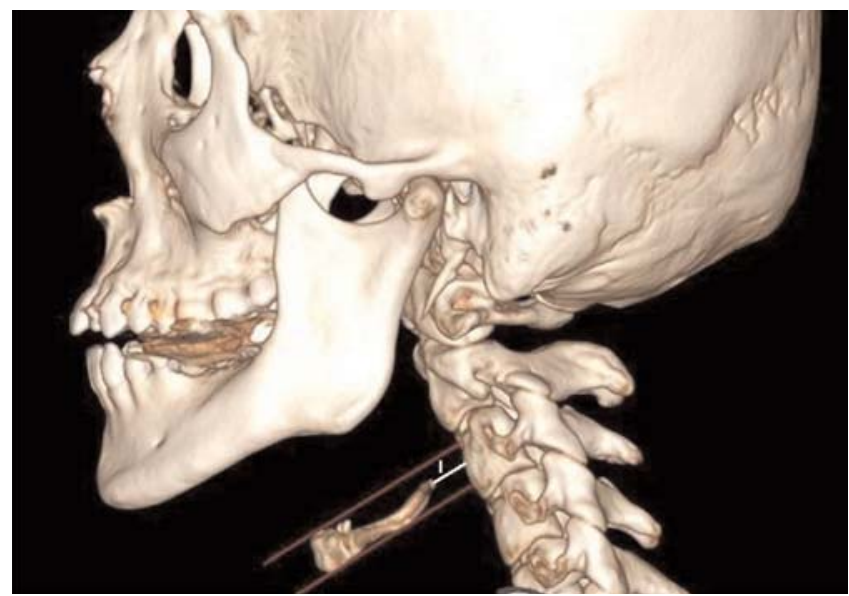

Figure 3. Left lateral view. I: the distance of the hyoid bone to the vertebral column. The lines used to determine the vertebral level of the hyoid bone are shown in red.

Statistical analyses were performed using the IBM SPSS Statistics for Windows (Version 20.0, Armonk, NY, USA). Frequency analysis was performed to determine the frequency of the vertebra level for each decade and both genders. The averages and standard deviations of all parameters by decades and genders were determined. In pairwise comparisons, the independent samples T-test was used for normally distributed data, while the Mann-Whitney U test was used for non-normally distributed data. Kruskal-Wallis test was used for comparison between the decades, because more than two independent groups were which were not normally distributed. The significance level was taken as $\mathrm{p}<0.05$.

\section{Results}

The vertebral level of the hyoid bone among genders are presented in Table 2 , and the minimum, maximum values, and averages of the mesurements are presented in Table 3. The most common vertebral levels were $\mathrm{C} 3$ and $\mathrm{C} 2-\mathrm{C} 3$ in females by $35.7 \%$ and $\mathrm{C} 3$ in males by $38.5 \%$, respectively, and the rarest vertebral levels were between $\mathrm{C} 1-\mathrm{C} 2$ and $\mathrm{C} 4-\mathrm{C} 5$ in females by $0.9 \%$ and $\mathrm{C} 5$ in males by $0.9 \%$. The average distance of the hyoid bone to the vertebral column was higher in males compared to females, although it was not statistically significant. No statistically significant difference was found between genders concerning the angle between right and left greater horns $(\alpha)$ and the distance of the hyoid bone to the vertebral column (I) (Figure 3). In other parameters, the values in males were statistically significantly higher $(\mathrm{p}<0.05)$ (Table 4$)$. The length and height of the greater horn on the right and left sides had no statistically significant difference.

The frequency of vertebral levels by decades is presented in Table 5, and the comparison of morphometric measurements by decades is presented in Table 6 . The vertebral level of the hyoid bone was getting lower as the age increased. In the comparison between the decades, a statistically significant difference was found between some decades for other parameters except for the parameters of the distance of the hyoid bone to the vertebral column (I) and the angle between right and left greater horn $(\alpha)$ (Table 6).

\section{Discussion}

There is a limited number of studies examining the morphometry and position of the hyoid bone according to the vertebral level. The possibility that the hyoid bone fractures may damage vital anatomical structures due its position, thus, any study on hyoid bone will be important. ${ }^{[10]}$ The hyoid bone fracture is a clinical condition that is difficult to diagnose and can usually be overlooked. If the hyoid bone fracture is clinically suspected in a patient with

Table 2

Frequency and percentages of vertebral levels by gender.

\begin{tabular}{|c|c|c|c|c|c|c|}
\hline Vertebral level & $\begin{array}{l}\text { Frequency } \\
\text { (female) }\end{array}$ & $\begin{array}{l}\text { Percentage (\%) } \\
\text { (female) }\end{array}$ & $\begin{array}{l}\text { Frequency } \\
\text { (male) }\end{array}$ & $\begin{array}{l}\text { Percentage (\%) } \\
\text { (male) }\end{array}$ & $\begin{array}{l}\text { Frequency } \\
\text { (total) }\end{array}$ & $\begin{array}{c}\text { Percentage (\%) } \\
\text { (total) }\end{array}$ \\
\hline $\mathrm{C} 1-\mathrm{C} 2$ & 1 & 0.9 & - & - & 1 & 0.5 \\
\hline $\mathrm{C2}$ & 4 & 3.6 & - & - & 4 & 1.9 \\
\hline $\mathrm{C} 2-\mathrm{C} 3$ & 40 & 35.7 & 18 & 17.3 & 58 & 26.9 \\
\hline C3 & 40 & 35.7 & 40 & 38.5 & 80 & 37.0 \\
\hline C3-C4 & 18 & 16.1 & 30 & 28.9 & 48 & 22.2 \\
\hline C4 & 8 & 7.1 & 10 & 9.6 & 18 & 8.3 \\
\hline C4-C5 & 1 & 0.9 & 5 & 4.8 & 6 & 2.8 \\
\hline $\mathrm{C5}$ & - & - & 1 & 0.9 & 1 & 0.5 \\
\hline Total & 112 & $100(\%)$ & 104 & $100(\%)$ & 216 & $100(\%)$ \\
\hline
\end{tabular}

C: cervical vertebra. 
Table 3

Minimum-maximum and average values of the measurements.

\begin{tabular}{|c|c|c|c|c|c|c|}
\hline Measurements & $\mathrm{n}$ & $\begin{array}{l}\text { 1st researcher } \\
\text { (mean) }\end{array}$ & $\begin{array}{l}\text { 2nd researcher } \\
\text { (mean) }\end{array}$ & $\min$ & $\max$ & mean $\pm S D$ \\
\hline A & 216 & 37.4 & 35.5 & 23.9 & 49.7 & $36.45 \pm 4.71$ \\
\hline B & 216 & 29.14 & 27.3 & 15.4 & 40.8 & $28.22 \pm 3.87$ \\
\hline C & 216 & 29.36 & 26.4 & 16.2 & 39.0 & $27.88 \pm 3.84$ \\
\hline D & 216 & 8.02 & 8 & 1.00 & 10.73 & $8.01 \pm 2.20$ \\
\hline $\mathrm{E}$ & 216 & 8.22 & 7.8 & 1.02 & 10.77 & $8.01 \pm 1.84$ \\
\hline $\mathrm{F}$ & 216 & 22.61 & 23.03 & 12.3 & 33.8 & $22.82 \pm 3.77$ \\
\hline G & 216 & 9.96 & 9.9 & 7.13 & 10.59 & $9.93 \pm 0.61$ \\
\hline $\mathrm{H}$ & 216 & 40.3 & 39.5 & 22.4 & 58.0 & $39.9 \pm 5.79$ \\
\hline I & 216 & 4.45 & 4.65 & .00 & 10.74 & $4.55 \pm 3.22$ \\
\hline$\alpha\left({ }^{\circ}\right)$ & 216 & 37.31 & 37.45 & .00 & 64.04 & $37.38 \pm 9.30$ \\
\hline
\end{tabular}

' $\alpha$ ' symbolizes angle, other measurements are milimeters.

Table 4

Comparison of parameters by gender.

\begin{tabular}{|c|c|c|c|c|c|c|c|c|c|c|c|}
\hline Gender & $\mathrm{n}$ & A & B & C & D & E & $\mathbf{F}$ & G & H & I & $\alpha\left(^{\circ}\right)$ \\
\hline Male & 104 & $39.01 \pm 4.54$ & $29.64 \pm 3.93$ & $29.34 \pm 3.99$ & $8.68 \pm 2.04$ & $8.55 \pm 1.48$ & $25.08 \pm 3.29$ & $10.18 \pm 0.34$ & $42.45 \pm 5.87$ & $4.78 \pm 3.22$ & $36.42 \pm 9.24$ \\
\hline Female & 112 & $34.08 \pm 3.47$ & $26.90 \pm 3.32$ & $26.52 \pm 3.15$ & $7.38 \pm 2.17$ & $7.51 \pm 2.01$ & $20.73 \pm 2.88$ & $9.70 \pm 0.61$ & $37.52 \pm 4.59$ & $4.34 \pm 3.21$ & $38.27 \pm 9.31$ \\
\hline$p$ & & $<0.001$ & $<0.001$ & $<0.001$ & $<0.001$ & $<0.001$ & $<0.001$ & $<0.001$ & $<0.001$ & 0.315 & 0.143 \\
\hline
\end{tabular}

' $\alpha$ ' symbolizes angle, other measurements are milimeters.

a neck injury, the diagnosis should be confirmed by CT, laryngoscopy, and surgical examination. ${ }^{[1]}$

In previous studies, it has been reported that the vertebral level of the hyoid bone is generally between the C2-C3 vertebra until the age of 10 and between the $\mathrm{C} 3-\mathrm{C} 4$ vertebra in adulthood. However, some studies reported that the position of the hyoid bone did not differ between genders. ${ }^{[1,13]}$

In this study, the vertebral level of the hyoid bone was getting lower as the age increased (Table 5). The most common vertebral levels were $\mathrm{C} 3$ and $\mathrm{C} 2-\mathrm{C} 3$ in females by $35.7 \%$ and $\mathrm{C} 3$ in males by $38.5 \%$, respectively, and the

Table 5

Vertebral level frequency according to decades.

\begin{tabular}{|c|c|c|c|c|c|c|c|c|c|}
\hline \multirow[b]{2}{*}{ Decade } & \multicolumn{8}{|c|}{ Frequency } & \multirow[b]{2}{*}{$\mathbf{n}$} \\
\hline & $\mathrm{C} 1-\mathrm{C} 2$ & $\mathrm{C} 2$ & $\mathrm{C} 2-\mathrm{C} 3$ & $\mathrm{C} 3$ & C3-C4 & $\mathrm{C} 4$ & $\mathrm{C} 4-\mathrm{C} 5$ & C5 & \\
\hline 2nd & - & 2 & 10 & 17 & 10 & - & 1 & - & 40 \\
\hline 3th & - & - & 3 & 7 & 1 & - & - & - & 11 \\
\hline 4th & - & 1 & 9 & 14 & 6 & 2 & - & - & 32 \\
\hline 5 th & 1 & - & 7 & 14 & 9 & 2 & 1 & - & 34 \\
\hline 6th & - & 1 & 5 & 10 & 8 & 5 & 1 & - & 30 \\
\hline 7 th & - & - & 10 & 6 & 4 & 1 & 2 & - & 23 \\
\hline 8th & - & - & 6 & 6 & 4 & 3 & 1 & - & 20 \\
\hline 9th & - & - & 7 & 3 & 5 & 3 & - & - & 18 \\
\hline 10th & - & - & 1 & 3 & 1 & 2 & - & 1 & 8 \\
\hline Total & 1 & 4 & 58 & 80 & 48 & 18 & 6 & 1 & 216 \\
\hline
\end{tabular}

C: cervical vertebra. 
Table 6

Comparison of measurements by decades

\begin{tabular}{lccccccccccc} 
Decade & $\mathbf{N}(\mathbf{2 1 6})$ & $\mathbf{A}$ & $\mathbf{B}$ & $\mathbf{C}$ & $\mathbf{D}$ & $\mathbf{E}$ & $\mathbf{F}$ & $\mathbf{G}$ & $\mathbf{H}$ & $\mathbf{I}$ & $\boldsymbol{\alpha}\left(\mathbf{(}^{\circ}\right)$ \\
\hline 2nd & 40 & $33.34 \pm 4.83$ & $24.73 \pm 4.19$ & $24.02 \pm 3.65$ & $6.92 \pm 1.50$ & $6.87 \pm 1.39$ & $19.69 \pm 3.01$ & $9.45 \pm 0.85$ & $38.01 \pm 5.64$ & $5.20 \pm 2.96$ & $38.19 \pm 8.78$ \\
\hline 3th & 11 & $35.41 \pm 4.05$ & $27.75 \pm 2.93$ & $27.82 \pm 3.15$ & $7.70 \pm 1.49$ & $7.32 \pm 1.82$ & $21.94 \pm 3.20$ & $9.38 \pm 0.78$ & $38.89 \pm 5.56$ & $3.86 \pm 3.47$ & $34.75 \pm 8.67$ \\
\hline 4th & 32 & $36.69 \pm 4.03$ & $28.54 \pm 3.34$ & $28.43 \pm 3.10$ & $7.66 \pm 2.83$ & $8.25 \pm 1.40$ & $22.82 \pm 3.51$ & $9.93 \pm 0.53$ & $38.74 \pm 5.44$ & $4.18 \pm 3.12$ & $34.07 \pm 10.67$ \\
\hline 5th & 34 & $37.25 \pm 4.78$ & $29.33 \pm 3.84$ & $28.62 \pm 3.39$ & $8.91 \pm 1.36$ & $8.59 \pm 1.53$ & $23.57 \pm 3.85$ & $10.05 \pm 0.46$ & $41.30 \pm 5.48$ & $3.76 \pm 2.84$ & $38.78 \pm 7.62$ \\
\hline 6th & 30 & $38.59 \pm 4.18$ & $29.57 \pm 2.62$ & $29.62 \pm 3.25$ & $8.38 \pm 2.49$ & $8.23 \pm 1.98$ & $24.63 \pm 3.78$ & $10.08 \pm 0.37$ & $41.86 \pm 5.61$ & $4.85 \pm 3.33$ & $36.92 \pm 10.84$ \\
\hline 7th & 23 & $36.52 \pm 5.27$ & $28.71 \pm 3.25$ & $28.51 \pm 3.75$ & $8.13 \pm 2.33$ & $7.77 \pm 2.73$ & $24.08 \pm 3.74$ & $10.09 \pm 0.54$ & $39.95 \pm 4.95$ & $4.12 \pm 2.97$ & $38.08 \pm 8.75$ \\
\hline 8th & 20 & $39.01 \pm 3.91$ & $30.52 \pm 2.65$ & $30.68 \pm 2.99$ & $8.47 \pm 2.77$ & $9.11 \pm 1.58$ & $24.62 \pm 3.28$ & $10.23 \pm 0.18$ & $41.57 \pm 7.64$ & $5.46 \pm 3.81$ & $38.27 \pm 8.60$ \\
\hline 9th & 18 & $35.05 \pm 3.38$ & $27.81 \pm 3.25$ & $27.30 \pm 3.10$ & $7.72 \pm 2.07$ & $8.41 \pm 1.64$ & $21.70 \pm 1.92$ & $10.19 \pm 0.09$ & $38.24 \pm 4.57$ & $5.14 \pm 3.69$ & $39.96 \pm 8.00$ \\
\hline 10th & 8 & $37.72 \pm 3.70$ & $28.96 \pm 2.16$ & $27.85 \pm 2.51$ & $9.12 \pm 0.93$ & $7.49 \pm 1.18$ & $24.20 \pm 3.50$ & $10.23 \pm 0.17$ & $41.42 \pm 6.83$ & $3.66 \pm 3.53$ & $35.90 \pm 12.63$ \\
\hline p & & $<0.001$ & $<0.001$ & $<0.001$ & $<0.001$ & $<0.001$ & $<0.001$ & $<0.001$ & 0.028 & 0.472 & 0.313 \\
\hline
\end{tabular}

' $\alpha$ ' symbolizes angle, other measurements are milimeters. A: difference between groups (2.-5., 2.-6., 2.-8. decades); B: difference between groups (2.-4., 2.-5., 2.-6., 2.-7., 2.-8. decades); C: difference between groups (2.-4., 2.-5., 2.-6., 2.-7., 2.-8. decades); D: difference between groups (2.-5., 2.-6., 2.-8. decades); E: difference between groups (2.-4., 2.-5., 2.-6., 2.-8. decades); F: difference between groups (2.-4., 2.-5., 2.-6., 2.-7., 2.-8. decades); G: difference between groups (2.-5., 2.-6., 2.-7., 2.-8., 2.-9., 3.-8, decades); H: difference between groups (2.-6. decades).

rarest vertebral levels were between $\mathrm{C} 1-\mathrm{C} 2$ and $\mathrm{C} 4-\mathrm{C} 5$ in females by $0.9 \%$ and $\mathrm{C} 5$ in males by $0.9 \%$ (Table 2 ).

The respiratory pattern and orthodontic treatments change the normal position of the head and the position of the hyoid bone. These changes in the position of the hyoid bone bring swallowing and respiratory problems. The hyoid bone is said to be more distant from the vertebral column in individuals with swallowing disorders. ${ }^{[1,14]}$ It was indicated that the distance of the hyoid bone to the cervical vertebra remained constant until puberty and that the hyoid bone moved away from the vertebra with age. ${ }^{[15]}$ Sahin Sağlam and Uydas, ${ }^{[16]}$ found a significant difference between genders in the distance of the hyoid bone to the vertebral column. In this study, we did not find a significant difference between the decades and genders in the distance of the hyoid bone to the vertebral column.

As a result of our measurements, the average distance of the hyoid bone to the vertebral column was higher in males compared to females, although it was not statistically significant. We consider that the reason for this may be the fact that the laryngeal prominenceis more prominent in males and slightly brings the hyoid bone forward through the thyrohyoid ligament. Studies have shown that the size of the hyoid bone is statistically significantly smaller in women than in men. ${ }^{[17,18]}$ The differentiation of the hyoid bone morphometry between genders contributes to the determination of gender in forensic medicine ${ }^{[2,19]}$ The present study revealed that the size of the hyoid in females is significantly smaller, except for the distance of the hyoid bone to the vertebral column and the angle between right and left greater horns (Table 4). We observed that there were statistically significant differ- ences in some parameters when compared between the decades (Table 6). We consider that the reason why 3 rd and 4th decades were the decades when the angle between right and left greater horn was the narrowest was the consequent ossification of the laryngeal cartilage with age resulting in narrowing of the thyroid angle (Table 6).

The studies on the morphometric characteristics of the hyoid bone and comparisons of the studies between genders are presented in Table 7. The fact that we obtained very close results with the studies using cadaver as a material also indicates that the measurements performed on 3D-CT images are very close to reality. We suggest that 3D-CT can make a significant and detailed contribution to morphological and morphometric analysis in the evaluation of the hyoid bone, especially in forensic medicine.

This study had several limitations. First, the nature of the study was retrospective. Second, because the study was retrospective, the movement of the hyoid bone in situations such as breathing, speech, and swallowing could not be defined and the parameters could not be measured in these positions. Thirdly, the study had a relatively small sample size.

\section{Conclusion}

Although the importance of the hyoid bone has been understood over the years, the studies examining its radiological anatomy and vertebral level are limited. CT is a useful imaging method to evaluate the normal anatomy of the bone and to recognize complications that may occur after the hyoid bone fracture and radiotheraphy, both in forensic medicine and in clinical practice. 
Dursun A et al.

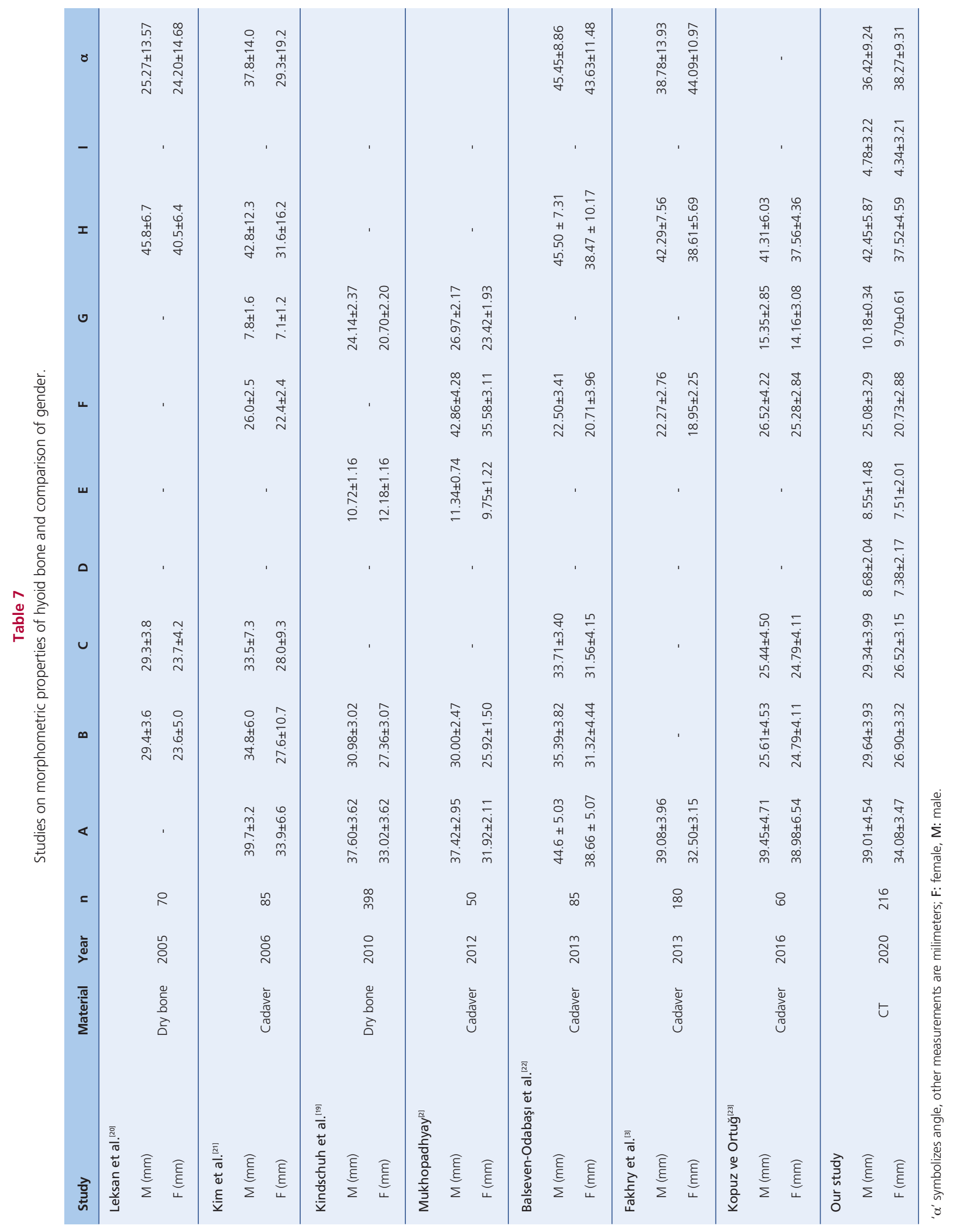




\section{Conflict of Interest}

The authors declare that they have no conflict of interest.

\section{Author Contributions}

$\mathrm{AD}$ : project development, data collection, data analysis, manuscript writing; MA: data collection, data analysis, manuscript writing; VAA: data collection, data analysis, manuscript writing; YK: data analysis, manuscript writing, manuscript editing; KÖ: data analysis, manuscript writing, manuscript editing; SA: manuscript writing, manuscript editing.

\section{Ethics Approval}

Approval was obtained from the Clinical Research Ethics Committee of Süleyman Demirel University, Faculty of Medicine (Date: 06/25/2019, Decision No: 200).

\section{Funding}

This research received no specific grant from any funding agency in the public, commercial, or not-forprofit sectors.

\section{References}

1. Soerdjbalie-Maikoe V, Van Rijn RR. Embryology, normal anatomy, and imaging techniques of the hyoid and larynx with respect to forensic purposes: a review article. Forensic Sci Med Pathol 2008;4: $132-9$.

2. Mukhopadhyay PP. Determination of sex from an autopsy sample of adult hyoid bones. Med Sci Law 2012;52:152-5.

3. Fakhry N, Puymerail L, Michel J, Santini L, Lebreton-Chakour C, Robert D, Giovanni A, Adalian P, Dessi P. Analysis of hyoid bone using 3D geometric morphometrics: an anatomical study and discussion of potential clinical implications. Dysphagia 2013;28:435-5.

4. Auvenshine RC, Pettit NJ. The hyoid bone: an overview. Cranio 2020;38:6-14.

5. Kraaijenga SAC, van der Molen L, Heemsbergen WD, Remmerswaal GB, Hilgers FJM, van den Brekel MWM. Hyoid bone displacement as parameter for swallowing impairment in patients treated for advanced head and neck cancer. Eur Arch Otorhinolaryngol 2017;274:597-606.

6. Stern N, Jackson-Menaldi C, Rubin AD. Hyoid bone syndrome: a retrospective review of 84 patients treated with triamcinolone acetonide injections. Ann Otol Rhinol Laryngol 2013;122:159-62.

7. Bhide AR, Dehadray AY. Excision of the greater cornu of the hyoid in hyoid syndrome. Auris Nasus Larynx 1980;7:1-6.

ORCID ID:

A. Dursun 0000-0003-4568-8761; M. Ayazoğlu 0000-0001-9027-7633; V. A. Ayylldz 0000-0003-0252-9023; Y. Kastamoni 0000-0002-3504-5853; K. Öztürk 0000-0002-5552-8684; S. Albay 0000-0001-8438-8628
8. Kasprzak H, Podbielska H, von Bally G, Fechner G. Biomechanical investigation of the hyoid bone using speckle interferometry. Int J Legal Med 1993;106:132-4.

9. Sawatari Y, Alshamrani Y. Oral and maxillofacial surgery cases concurrent hyoid bone fracture associated with multiple facial fractures secondary to assault: case report and review of literature. Oral and Maxillofacial Surgery Cases 2019;5:100119.

10. Bolatlı G, Dogan NÜ, Fazlıogulları Z, Kıvrak AS, Uysal Iİ, Karabulut AK, Paksoy Y. The evaluation of variations of the hyoid bone with multidetector computerized tomography. Tropical Health and Medical Research 2020;2:1-8.

11. Samieirad S, Rayeni AS, Tohidi E. A rare case of hyoid bone fracture concomitant with a comminuted mandibular fracture. J Maxillofac Oral Surg 2020;19:40-3.

12. Bibby RE, Preston CB. The hyoid triangle. Am J Orthod 1981;80: 92-7.

13. Ceylan I, Gunnar A. The Study of the natural head and hyoid bone positions of the subjects having different vertical facial development. Turkish Journal of Ortodontics 1995;8:165-71.

14. Cleal CF. Deglutition: a study of form and function. Am J Orthod 1965;51:566-94.

15. Durzo CA, Brodie AG. Growth behavior of the hyoid bone. Angle Orthod 1962;32:193-204.

16. Sahin Sağlam AM, Uydas NE. Relationship between head posture and hyoid position in adult females and males. J Craniomaxillofac Surg 2006;34:85-92.

17. Pollanen MS, Ubelaker D. Forensic significance of the polymorphism of hyoid bone shape. J Forensic Sci 1997;42:890-2.

18. Shimizu Y, Kanetaka H, Kim YH, Okayama K, Kano M, Kikuchi M. Age-related morphological changes in the human hyoid bone. Cells Tissues Organs 2005;180:185-92.

19. Kindschuh SC, Dupras TL, Cowgill LW. Determination of sex from the hyoid bone. Am J Phys Anthropol 2010;143:279-84.

20. Lekšan I, Marcikić M, Nikolić V, Radić R, Selthofer R. Morphological classification and sexual dimorphism of hyoid bone: new approach. Coll Antropol 2005;29:237-42.

21. Kim DI, Lee UY, Park DK, Kim YS, Han KH, Kim KH, Han SH. Morphometrics of the hyoid bone for human sex determination from digital photographs. J Forensic Sci 2006;51:979-84.

22. Balseven-Odabasi A, Yalcinozan E, Keten A, Akcan R, Tumer AR, Onan A, Canturk N, Odabasi O, Dinc AH. Age and sex estimation by metric measurements and fusion of hyoid bone in a Turkish population. J Forensic Leg Med 2013;20:496-501.

23. Kopuz C, Ortug G. Variable morphology of the hoyid bone in Anatolian population: clinical implications - a cadaveric study. International Journal of Morphology 2016;34:1396-403.

Correspondence to: Mehtap Ayazoğlu, $\mathrm{PhD}(\mathrm{c})$

Department of Anatomy, Faculty of Medicine, Süleyman Demirel University, Isparta, 32260, Turkey

Phone: +902462113307

e-mail: ayazoglumehtap@outlook.com

Conflict of interest statement: No conflicts declared.

This is an open access article distributed under the terms of the Creative Commons Attribution-NonCommercial-NoDerivs 4.0 Unported (CC BY-NCND4.0) Licence (http://creativecommons.org/licenses/by-nc-nd/4.0/) which permits unrestricted noncommercial use, distribution, and reproduction in any medium, provided the original work is properly cited. How to cite this article: Dursun A, Ayazoğlu M, Ayylldız VA, Kastamoni Y, Öztürk K, Albay S. Morphometry of the hyoid bone: a radiological anatomy study. Anatomy 2021;15(1):44-51. 